\title{
O uso da conferência familiar na resolução de conflitos de uma família com idosa dependente
}

Case Report

\author{
The use of the family conference in the conflict resolution \\ of a family with a dependent elderly woman
}

Julieta Cunha Martins Lima ${ }^{1}$ Gerídice Lorna Andrade de Moraes ${ }^{2}$ Rômulo Fernandes Augusto Filho ${ }^{3}$

\begin{abstract}
Resumo
A conferência familiar constitui-se em uma estratégia importante na abordagem a famílias com pessoas idosas dependentes. Uma equipe de saúde da família do Centro de Saúde da Família Francisco Domingos da Silva, Fortaleza, Ceará, realizou conferência familiar de uma família com uma idosa dependente de cuidados. Encontramos falta de envolvimento e resistência dos filhos no cuidado da idosa e sobrecarga do cuidador, que desejava internar a mãe em um asilo. Com o objetivo de esclarecer sobre direitos e deveres dos familiares de idosos dependentes e buscar soluções para uma melhor distribuição de tarefas na atenção à saúde da paciente, foi realizada a conferência familiar. Os próprios familiares relataram a importância do encontro e o papel dos profissionais na adoção de medidas que melhoraram a situação de convivência e a dinâmica familiar.
\end{abstract}

\begin{abstract}
The family conference constitutes an important approach to assessing families with care-dependent elderly people. A health team of the Family Health Center Francisco Domingos da Silva, Fortalera, Ceará, conducted a family conference to assess a family with a dependent elderly woman. We observed a lack of involvement and resistance of the sons to providing care to the elderly woman. The only son who acted as caregiver felt overburdened and wanted to place his mother in a long-term facility for elderly people. Our goals were to elucidate the rights and duties of family members of dependent elderly and to seek for a better way of distributing the duties related to the care of the dependent elderly person. The family members recognized the importance of the meeting and the role of health professionals in adopting measures to provide better communication among the family members and to improve family dynamics.
\end{abstract}

Palavras-chave: Serviços de Saúde para Idosos; Medicina de Família e Comunidade; Direitos dos Idosos; Acolhimento.
Key Words: Health Services for the Aged; Family Practice; Aged Rights;

User Embracement.

${ }^{1}$ Médica residente em Medicina de Família e Comunidade, Sistema Municipal de Saúde Escola de Fortaleza, Fortaleza, Ceará Brasil. ${ }^{2}$ Enfermeira, mestre e doutoranda em Saúde Comunitária, Universidade Federal do Ceará, Fortaleza, Ceará Brasil.

${ }^{3}$ Médico de Família e Comunidade, Sistema Municipal de Saúde Escola de Fortaleza, Fortaleza, Ceará Brasil.

129 Rev Bras Med Fam e Com

Rio de Janeiro, v.4, n⿳14, jul /set 2008 


\section{Introdução}

Com o aumento da longevidade, é crescente o surgimento de doenças crônicas e limitações funcionais. É frequentemente observada a presença de demência, fraturas de quadril, sequelas de acidente vascular cerebral, doenças reumatológicas e deficiências visuais na população idosa ${ }^{1,2}$.

O cuidado aos idosos dependentes é debatido em diversos países de forma diferente. Em alguns países, o cuidado é predominantemente familiar e, em outros, os encargos ficam por conta do Estado. No Brasil, o cuidado tem sido prestado por um sistema de suporte informal, que inclui familiares, amigos, vizinhos e membros da comunidade, cujas atividades são, em geral, prestadas voluntariamente, sem remuneração ${ }^{1,2}$.

O Estado garante, por meio da Política Nacional do Idoso em vigor desde 1994 e do Estatuto do Idoso em vigor desde 2003, a promoção do envelhecimento saudável, a manutenção e a melhoria da capacidade funcional dos idosos, a prevenção de doenças, a recuperação da saúde dos que adoecem e a reabilitação daqueles que venham a ter a sua capacidade funcional restringida, de modo a garantir-lhes permanência no meio em que vivem, exercendo de forma independente suas funções na sociedade ${ }^{3,4,5}$.

A família, apontada pela Constituição Federal Brasileira, pela Política Nacional do Idoso e pela Política Nacional de Saúde do Idoso, é responsável pelos cuidados ao idoso. A equipe de saúde da família é fundamental para dar suporte a esta família cuidadora ${ }^{6}$. Várias tecnologias leves podem ser utilizadas pela equipe como: o acolhimento, tendo a escuta qualificada como ponto essencial na criação de vínculos e cumplicidade entre profissionais e usuários, a clínica ampliada, a abordagem centrada na pessoa, além de visitas domiciliares, com o reconhecimento in loco das condições biopsicossociais da população acompanhada e conferências familiares na abordagem de situações mais complexas.

Os papéis da equipe de saúde da família com relação aos idosos são: o conhecimento da realidade das famílias pelas quais são responsáveis; identificação dos problemas de saúde e situações de risco mais comuns aos quais o idoso está exposto e elaboração de um plano local para o enfrentamento dos mesmos; execução dos procedimentos de vigilância à saúde da pessoa idosa; valorização das relações com a pessoa idosa e sua família, para a criação de vínculo de confiança, de afeto e de respeito ${ }^{6}$.

A conferência familiar é definida como um nível de abordagem a famílias com situações de conflitos familiares, abordando condições de saúde e de interação/comunicação entre membros da família. Marca o início do aconselhamento, em que o profissional sente-se confortável em abordar condições de saúde e sentimentos familiares, atuando como moderador ${ }^{7}$.

O profissional de saúde, utilizando a conferência familiar como forma de abordagem de situações complexas, tem a possibilidade de educar a família sobre o problema, permitir aos membros familiares a expressão e compartilhamento de sentimentos e ajudá-los a encontrar suporte, seja na equipe de saúde da família ou em instituições de apoio a idosos e cuidadores, além de realizar referências a outros níveis de atenção.

O presente trabalho tem como objetivo relatar uma experiência na qual a conferência familiar foi bem sucedida na abordagem de conflitos de uma família com idosa dependente.

\section{Desenvolvimento}

A abordagem aos idosos dependentes e seus cuidadores na Equipe Azul do Centro de Saúde da Família Francisco Domingos da Silva em Fortaleza, Ceará, é feita por meio do acolhimento na Unidade de Saúde, das visitas domiciliares, do grupo de idosos, que visa à promoção da saúde, e do grupo de cuidadores, que tem o objetivo de dar suporte e orientações sobre o cuidado.

Relataremos o caso de um filho que solicitou visita domiciliar por estar se sentindo sobrecarregado nos cuidados de sua mãe idosa dependente e insatisfeito com o fato de seus irmãos não o ajudarem em relação aos cuidados da mãe. Os nomes utilizados para a descrição do caso que se segue são fictícios.

O contexto familiar era de uma família estendida, com três gerações morando no mesmo lar, em que os mem- 
bros dependiam da aposentadoria da paciente Socorro, 68 anos, hipertensa, com afasia e hemiplegia à direita, decorrentes de sequela de Acidente Vascular Cerebral (AVC), dependente totalmente de cuidados. Na casa, vivem Socorro, seu filho mais novo, Felipe, sua nora, Ana, e seu neto lactente. Socorro tem outros dois filhos mais velhos, André e Antônio, que moram próximo à sua casa e têm famililia constituída. A relação entre o cuidador e seus irmãos é conflituosa.

Para melhor entendimento da dinâmica familiar, foi usado o modelo PRACTICE, que consiste em uma ferramenta para avaliação das famílias ${ }^{8}$.
C - communication (comunicação): satisfatória entre o casal com resolução dos problemas entre eles, mas é prejudicada entre os irmãos, ocorrendo inclusive agressões verbais André e Antônio acusam o casal cuidador de estar usufruindo da aposentadoria e casa da mãe;

$\mathbf{T}$ - time in life cicle (tempo no ciclo de vida): família estendida com três gerações morando no mesmo lar;

I - illness in family (doenças na família): Socorro é hipertensa com sequelas decorrentes de AVC, dependente totalmente de cuidados;

C - coping with stress (enfrentando o estresse): a família procura

Figura 1. Genograma da família.

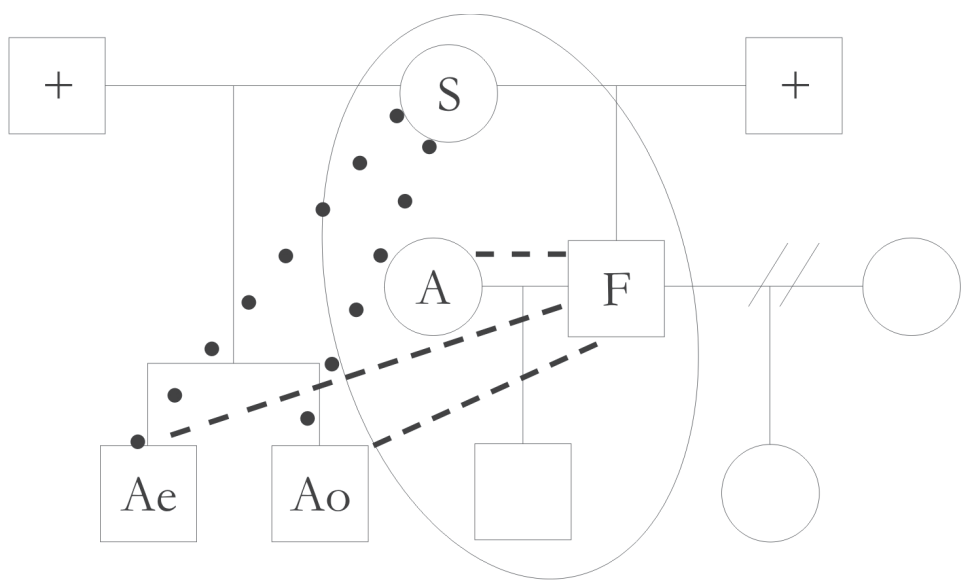

\section{Legenda:}

$\begin{aligned} & \square \text { Sexo Masculino } \\ & \text { S Sexo Femino } \\ & \text { S Socorro } \\ & \text { F Felipe } \\ & \text { Ao Antônio } \\ & \text { Ae André }\end{aligned}$

P - preseting problem (problema apresentado): sobrecarga do cuidador e desejo de levar a idosa ao asilo;

$\mathbf{R}$ - roles (papéis): Felipe é cuidador da mãe idosa dependente e está desempregado. A renda da família é a aposentadoria de Socorro;

$\mathbf{A}$ - affect (afeto): existe cumplicidade entre o casal cuidador e a idosa, mas há uma relação conflituosa entre os irmãos;
A Ana

+ Falecido

* Separação

- Relação Conflituosa

... Relação Distanciada

apoio na comunidade por intermédio de vizinhos e da equipe de saúde da família;

$\mathbf{E}-$ ecology (meio ambiente): a família reside em área de risco, em condições socioeconômicas desfavoráveis, onde há violência e tráfico de drogas.

De acordo com a Classificação da Escala de Avaliação Relacional Global (Global Assessment of Relational

131 Rev Bras Med Fam e Com Rio de Janeiro, v.4, n`14, jul /set 2008 
Functionting - GARF), já validada no Brasil ${ }^{9}$, o funcionamento da família foi classificado como nível 3, considerando que os interesses individuais não eram atendidos satisfatoriamente e que havia dificuldade de comunicação para a resolução dos conflitos familiares, apesar de haver algum apoio entre os membros.

Durante a visita domiciliar realizada à casa de D. Socorro para acompanhamento, duas questões surgiram como ponto central: a sobrecarga de Felipe e a falta de interesse dos outros filhos no cuidado em relação à idosa. Felipe manifestou interesse em internar sua mãe em um asilo e pediu informações a respeito do assunto aos profissionais de saúde. Para que fossem melhor esclarecidos os papéis de cada membro familiar no cuidado ao idoso dependente, foi sugerida a realização de uma conferência familiar em um ambiente neutro e que possibilitasse a participação dos outros filhos da paciente.

Os passos da conferência realizada seguiram estas etapas:

1. Agendamento das conferências entre os familiares e os profissionais da equipe de saúde.

2. Apresentação dos participantes no início da conferência. 3. Exposição da lista de problemas e dos objetivos.

4. Discussão e exposição de pontos de vista por parte dos familiares.

5. Tomada de decisões.

$\mathrm{Na}$ conferência familiar, participaram Felipe, sua esposa, Ana, o filho mais velho de Socorro, André, e os profissionais envolvidos na atenção domiciliar da paciente (enfermeira e dois médicos residentes). A enfermeira da equipe foi a moderadora do encontro.

No início, ocorreu a apresentação dos participantes. Em seguida, foi exposta a seguinte lista de problemas:

- Agressão verbal dos filhos mais velhos da paciente em relação ao cuidador e sua esposa; eles acusam o casal de se aproveitar da aposentadoria e da casa da idosa.

- Falta de envolvimento e resistência dos outros filhos no cuidado da idosa.

- Pressão por parte de Ana para que Felipe não seja o único responsável pelo cuidado da mãe. Ana inclusive ameaça separar-se de Felipe, que já enfrentou a separação de sua primeira esposa, com quem teve uma filha, atualmente com quatro anos de idade. $O$ motivo da separação, segundo Felipe, foi a sobrecarga de tarefas exigidas após a doença de Socorro.

- Sobrecarga do cuidador, que deseja internar a mãe em um asilo e reclama que não consegue trabalhar por conta do tempo despendido no cuidado da idosa e que já não aguenta a pressão da esposa e as acusações dos irmãos.

Em seguida, os objetivos da conferência familiar foram expostos: esclarecer sobre direitos e deveres dos familiares de idosos dependentes; buscar soluções para uma melhor distribuição de tarefas na atenção à saúde da paciente.

Iniciou-se, então, a discussão e a exposição dos pontos de vista dos familiares. Felipe e Ana expuseram sua situação de sobrecarga e pediram ajuda aos outros filhos no que tange ao cuidado à paciente. André, o filho mais velho, mostrou resistência em falar sobre o assunto e achava que Felipe deveria ser o responsável por todas as obrigações no cuidado da mãe, já que morava com ela.

A responsabilidade da família no cuidado do idoso foi esclarecida pelos profissionais de saúde e as seguintes propostas foram levantadas durante a discussão:

a) Os filhos contratariam uma pessoa para ajudar nos cuidados diários à idosa.

b) Revezamento dos filhos no cuidado da idosa. Felipe continuaria morando com a mãe, sendo responsável pelos cuidados nos dias úteis e, nos fins de semana, Socorro iria para a casa de André.

c) Felipe mudaria de domicílio com sua família. André passaria a morar com a mãe assumindo a responsabilidade integral no cuidado à paciente nos dias úteis e, nos fins de semana, Socorro iria para casa de Felipe.

d) Felipe continuaria envolvido nos cuidados à pacientesem a interferência dos outros filhos, com autonomia sobre as finanças, inclusive com a possibilidade de alugar outra casa em um bairro afastado dos outros filhos para morar com a mãe. 
A partir das propostas sugeridas durante a primeira conferência, foi então agendado novo encontro uma semana após o primeiro para reflexão das propostas e tomada de decisões.

A impressão que nós, profissionais da equipe, tivemos no primeiro encontro foi de que Felipe era o único interessado no cuidado da mãe e que André mostrava resistência em cooperar.

$\mathrm{Na}$ segunda conferência familiar, compareceram Felipe, Ana e profissionais de saúde (médica residente, enfermeira e duas agentes comunitárias de saúde). Felipe relatou que a família chegou a um consenso. Após a primeira conferência, os três filhos se reuniram e decidiram que a paciente receberia os cuidados de Antônio, que passaria a morar na casa da mãe com suas duas filhas adolescentes. Antônio trabalha no próprio domicílio, e, com o auxilio de suas filhas, seria possível a realização das tarefas domésticas e de cuidado com Socorro. Felipe deixaria a casa da mãe, passando a morar de aluguel em uma casa próxima, e ficaria responsável pelos cuidados da mãe durante os fins de semana.

Antes da conferência, percebemos que as relações familiares estavam bastante desgastadas em virtude das questões financeiras, da sobrecarga do cuidador e dos conflitos entre o casal cuidador e entre os irmãos. Os membros da família ressaltaram a importância da conferência na resolução do conflito e no favorecimento de uma convivência mais harmoniosa entre eles.

\section{Conclusão}

Utilizamos a conferência familiar como tecnologia assistencial por entender que a família necessitava de um suporte que proporcionasse segurança, confiança, esclarecimento sobre os cuidados da idosa dependente e auxílio na resolução dos problemas da família, levantando sugestões de possíveis caminhos a serem tomados dentro da comunidade.

A utilização da conferência familiar no presente caso mostrou-se eficaz para ajudar a familiar na resolução do conflito, favorecendo a autonomia, melhora da comuni- cação e convivência entre os membros.

Em uma visão prospectiva, é imprescindível considerar as políticas governamentais de saúde do idoso, mas não se pode esquecer da necessidade de capacitação dos profissionais que trabalham na estratégia Saúde da Família e de redes de apoio social às famílias com pessoas dependentes de cuidados na própria comunidade.

\section{Referências}

1. Almeida TL. Características dos cuidados de idosos dependentes no contexto da Saúde da Família. Dissertação, Ribeirão Preto, 2005.

2. Caldas CP. Envelhecimento com dependência: Responsabilidade e demandas da família. Cad. Saúde Pública. 2003; 19(3): 773-781.

3. Brasil. Constituição da República Federativa do Brasil. Senado Federal. Brasília (DF): Senado Federal; 1988.

4. Brasil. Política Nacional do Idoso, Lei no 8842 , de 4 de janeiro de 1994. Brasília (DF): Diário Oficial da República Federativa do Brasil, vol. 132, n 3, pp 77-9, Seção 1.

5. Brasil. Política Nacional de Saúde do Idoso, aprovada pela portaria $n^{\circ} 1395$, de 9 de dezembro de 1999. Brasília (DF): Diário Oficial da República Federativa do Brasil, $n^{\circ}$ 237-E, 20-24, 13 dez. Seção 1.

6. Silvestre JA, Neto MMC. Abordagem do idoso em programas de saúde da família. Cad. Saúde Pública. 2003;19(3): 839-847.

7. Coleman WL. Family-Focused Behavioral Pediatrics. 1.ed. Philadelphia: Lippincott Williams \& Wilkins Publishers; 2001. 8. Fernandes CLC, Curra LCD. Ferramentas de abordagem da família. In Programa de Atualização em Medicina de Família e Comunidade. Modulo 1. Porto Alegre (RS): ARTMED/PANAMERICANA; 2006. p.11-40.

9. Falceto OG, Busnello ED, Bozzetti MC. Validação de escalas diagnósticas do funcionamento familiar para utilização em serviços de atenção primária à saúde. Rev. Panam. Salud Pública. 2000; 7: 255-63. 


\section{Endereço para correspondência:}

Rua Monsenhor Bruno, 900

Apto. 101 - Bloco A

Meireles - Fortaleza (CE)

CEP: 60115-190

\section{Endereço eletrônico:}

jullymcunha@hotmail.com 